\title{
Communication
}

\section{Inhibiting the Growth of 3D Brain Cancer Models with Bio-Coronated Liposomal Temozolomide}

\author{
Giordano Perini ${ }^{1,2,+} \mathbb{D}^{\circ}$, Francesca Giulimondi ${ }^{3,+}$, Valentina Palmieri ${ }^{1,2,4}{ }^{(0)}$, Alberto Augello ${ }^{2}$, Luca Digiacomo ${ }^{3}$, \\ Erica Quagliarini ${ }^{5}$, Daniela Pozzi ${ }^{3}$, Massimiliano Papi ${ }^{1,2, *}$ (1) and Giulio Caracciolo ${ }^{3, * \mathbb{C}}$ \\ 1 Dipartimento di Neuroscienze, Università Cattolica del Sacro Cuore, Largo Francesco Vito 1, \\ 00168 Rome, Italy; giordano.perini@unicatt.it (G.P.); valentina.palmieri@unicatt.it (V.P.) \\ 2 Fondazione Policlinico Universitario A. Gemelli IRCSS, 00168 Rome, Italy; alberto.augello@unicatt.it \\ 3 Department of Molecular Medicine, Sapienza University of Rome, Viale Regina Elena 291, 00161 Rome, Italy; \\ francesca.giulimondi@uniroma1.it (F.G.); luca.digiacomo@uniroma1.it (L.D.); \\ daniela.pozzi@uniroma1.it (D.P.) \\ 4 Istituto dei Sistemi Complessi, CNR, Via dei Taurini 19, 00185 Rome, Italy \\ 5 Department of Chemistry, Sapienza University of Rome, P.le A. Moro 5, 00185 Rome, Italy; \\ erica.quagliarini@uniroma1.it \\ * Correspondence: massimiliano.papi@unicatt.it (M.P.); giulio.caracciolo@uniroma1.it (G.C.) \\ + These authors contribute equally to this paper.
}

check for updates

Citation: Perini, G.; Giulimondi, F.; Palmieri, V.; Augello, A.; Digiacomo, L.; Quagliarini, E.; Pozzi, D.; Papi, M.; Caracciolo, G. Inhibiting the Growth of 3D Brain Cancer Models with Bio-Coronated Liposomal Temozolomide. Pharmaceutics 2021, 13, 378. https://doi.org/10.3390/ pharmaceutics 13030378

Academic Editor: Fabio Pastorino

Received: 3 February 2021

Accepted: 5 March 2021

Published: 12 March 2021

Publisher's Note: MDPI stays neutral with regard to jurisdictional claims in published maps and institutional affiliations.

Copyright: (c) 2021 by the authors. Licensee MDPI, Basel, Switzerland. This article is an open access article distributed under the terms and conditions of the Creative Commons Attribution (CC BY) license (https:// creativecommons.org/licenses/by/ $4.0 /)$.

\begin{abstract}
Nanoparticles (NPs) have emerged as an effective means to deliver anticancer drugs into the brain. Among various forms of NPs, liposomal temozolomide (TMZ) is the drug-of-choice for the treatment and management of brain tumours, but its therapeutic benefit is suboptimal. Although many possible reasons may account for the compromised therapeutic efficacy, the inefficient tumour penetration of liposomal TMZ can be a vital obstacle. Recently, the protein corona, i.e., the layer of plasma proteins that surround NPs after exposure to human plasma, has emerged as an endogenous trigger that mostly controls their anticancer efficacy. Exposition of particular biomolecules from the corona referred to as protein corona fingerprints (PCFs) may facilitate interactions with specific receptors of target cells, thus, promoting efficient internalization. In this work, we have synthesized a set of four TMZ-encapsulating nanomedicines made of four cationic liposome (CL) formulations with systematic changes in lipid composition and physical-chemical properties. We have demonstrated that precoating liposomal TMZ with a protein corona made of human plasma proteins can increase drug penetration in a 3D brain cancer model derived from U87 human glioblastoma multiforme cell line leading to marked inhibition of tumour growth. On the other side, by fine-tuning corona composition we have also provided experimental evidence of a non-unique effect of the corona on the tumour growth for all the complexes investigated, thus, clarifying that certain PCFs (i.e., APO-B and APO-E) enable favoured interactions with specific receptors of brain cancer cells. Reported results open new perspectives into the development of corona-coated liposomal drugs with enhanced tumour penetration and antitumour efficacy.
\end{abstract}

Keywords: biomolecular corona; nanomedicine; drug delivery; glioblastoma; temozolomide

\section{Introduction}

Brain tumor is a health and social issue of considerable importance. It causes about $7 \%$ of cancer-related deaths for those under the age of 70 and it is the second most common form of cancer (after leukemia) for children and teens [1]. Among primary brain cancers, glioblastoma (GMB) is the most common and lethal form [2]. Despite aggressive therapy, this tumor is characterized by frequent relapse [3]. Surgical resection, followed by radiation with simultaneous chemotherapy, as part of a combined modality approach, is among the most frequent current treatments. Yet, although recent advances in handling many solid tumors, the treatment of GBM remains weak with a median survival of 12-15 
months [4]. Treatment limits derive from radiotherapy and chemotherapy resistance, side effects limiting treatments and, mostly, low drug concentration in the brain $[5,6]$. In fact, an arduous challenge in the management of brain tumor with drug administration is the drug tumor-targeting. As a matter of fact, to reach the brain, the drug needs to overcome the blood-brain barrier (BBB), a physical and electrostatic barrier that limits brain permeation of therapeutics $[7,8]$. Considering that, a special goal is increasing the bioavailability of traditional brain tumor chemotherapeutic drugs such as Temozolomide (TMZ), doxorubicin hydrochloride, irinotecan hydrochloride and vincristine sulfate [9-13]. Temozolomide (TMZ) is a chemotherapy drug that has been shown to improve average survival rate for people with some high-grade brain tumors. In clinical studies, temozolomide consistently demonstrates reproducible linear pharmacokinetics with approximately $100 \%$ p.o. bioavailability, noncumulative minimal myelosuppression that is rapidly reversible and activity against a variety of solid tumors in both children and adults [14]. However, in aggressive tumors, TMZ treatment is rarely successfully curative, because of tumor's high resistance to therapy and low drug bioavailability in tumor tissue. [15] Thus, new alternatives are necessary, including tumor cells-targeted approaches through the use of directed vectors that are able to be transported across the BBB and accumulate in the target tissue. One approach towards increasing drug accumulation in cells, is to escape from their efflux mechanism by encapsulating drugs into nano-scaled vehicles [16], e.g., poly(D,Llactide-co-glycolide) (PLGA) [17], chitosan nanogel [18], iron oxide nanoparticles [19,20] and lipid nanoparticles [21]. Indeed, one of the most promising and versatile strategies makes use of nanoparticles (NPs) acting as drug delivery systems since they provide both protection to therapeutic agents and efficient delivery across the BBB [22]. Among different nano-vehicles, liposomes are considered potent nanocarriers systems for controlled drug release $[22,23]$. This is mainly due to their non-toxic nature, biocompatibility, size, specificity and membrane permeability. For instance, Patel and Parikh have compared the anti-cancer efficiency of free TMZ and TMZ loaded in Hydro Soy L- $\alpha$-phosphatidylcholine (HSPC) liposome for the GBM management through cell culture technique [22]. Their results suggested that liposomal formulation enhances the availability of drug at the specific site and reduces the dose-related toxicity of chemotherapy. However, despite the success of liposomal formulations in vivo, their translation into clinic has progressed more slowly. Indeed, these delivery systems are prone to elimination from the bloodstream, limiting their therapeutic efficacy. This clearance may be due to several factors including opsonization of plasma proteins or uptake by fixed macrophages. Thus, to overcome this limitations, newer generation of liposomes have employed a combination of sterically stabilized and ligandtargeted liposomes to enhance their circulation times in blood and assure a site-specific release. For example, in a recent study, it has been demonstrated that multi-targeting liposome based on glucose and biotin showed a more consistent cellular uptake of glioma cells than uncoated liposomes [24]. Yet, in the clinic, most of these data still remain unavailable for many nanomedicines. This is principally owed to the wrong assumption that liposomes will directly interact with cell surface once administrated. This is principally owed to the wrong assumption that liposomes will accumulate at the target site once administrated [25]. In the last decade, on average, less than $1 \%$ of the dispensed dosage of nanomaterials has been found within a solid tumor [26]. This poor accumulation ability has harmful influence on the clinical translation of nanomaterials for human use with respect to cost, toxicity and therapeutic outcome. After ten years of intense investigation, we now know that the poor translation of liposomes from benchtop to patient's bedside is mainly due to our lack of knowledge of the bionano interactions, i.e., the interactions between nanosized liposomes and biological systems [27,28]. In fact, a common factor that is often ignored when dealing with the synthesis of drug delivery systems is testing their behavior in biological fluids [29]. Although an efficient translation of a drug delivery system relies on rigorous control over its physicochemical characteristic such as size, charge, morphology etc., these parameters are often altered upon contact with biological media. Following intravenous administration, liposomes interact with biological molecules present in blood which ad- 
sorb on their surface forming a "corona" [30-32]. This biomolecular corona (BC) alters the synthetic identity of the nanosystems conferring a new identity that mostly controls their biological activity (e.g., blood residency, biodistribution, immune system recognition, cell binding and intracellular fate) $[27,33,34]$. Furthermore, the exposition of particular biomolecules from the corona may facilitate interactions with specific receptors [35-37]. Currently, it is known that liposomes interact and bind to receptors at the BBB level [38]. Thus, it is maturing the idea that BC-based nano-delivery systems could be suitable for innovative treatments of brain-related diseases [39,40]. Consequently, to make the most of these novel aspects and generate an efficient drug delivery system for brain-targeting, it is essential to investigate whether the BC supports liposome-based brain targeting [41]. As a step to clarify this matter, this work was aimed at exploring the effect of $\mathrm{BC}$ on the drug penetration and anticancer activity of liposomal TMZ. We tackled this issue by employing four TMZ-encapsulating cationic liposomal (CL) formulations made of binary combinations of the cationic lipids 1,2-dioleoyl-3-trimethylammonium-propane (DOTAP) and $3\left(-\left[\mathrm{N}-\left(\mathrm{N}^{\prime}, \mathrm{N}^{\prime}\right.\right.\right.$-dimethylaminoethane)-carbamoyl]-cholesterol (DC-Chol) and neutral lipids dioleoylphosphatidylethanolamine (DOPE) and cholesterol (Table 1). This formulation was chosen according to previous findings as it exhibits unusual endosomal escape that results in high performances and potential applicability in difficult-to-transfect cells [42-45].

Table 1. Lipid compositions of TMZ-loaded CLs.

\begin{tabular}{ccccc}
\hline Sample Name & DOTAP (mol \%) & DC-Chol (mol \%) & DOPE (mol \%) & Chol (mol \%) \\
\hline CL1 & 50 & 0 & 0 & 50 \\
CL2 & 50 & 0 & 50 & 0 \\
CL3 & 0 & 50 & 50 & 0 \\
CL4 & 0 & 50 & 0 & 50 \\
\hline
\end{tabular}

Research on brain cancer drug response has historically been performed using commercially available 2D cell cultures that poorly predict in vivo cellular responses. In recent years, 3D cell culture techniques have been largely investigated and became a suitable alternative to traditional cell culture methods $[1,46,47]$. GBM tumor growth develops around three different areas, a proliferative outer region, a hypoxic core and a permeable vasculature. Currently, it has become apparent that $3 \mathrm{D}$ cultures reproduce more faithfully GBM features, from its spatial distribution to its interaction with the surrounding microenvironment [48]. Furthermore, 3D cultures are generally more resistant to chemotherapy [49]. Therefore, here we tested TMZ-loaded CLs on a 3D brain cancer model derived from U87 human glioblastoma multiforme cell line.

\section{Materials and Methods}

\subsection{Preparation of TMZ-Loaded CLS}

1,2-Dioleoyl-3-trimethylammonium-propane (DOTAP), (3-[N-( $\mathrm{N}^{\prime}, \mathrm{N}^{\prime}$-dimetylaminoethane)carbamoyl])-cholesterol (DC-Chol), dioleoylphosphatidylcholine (DOPC) and dioleoylphosphatidylethanolamine (DOPE) were purchased from Avanti Polar Lipids (Alabaster, AL, USA). Cationic lipids were used in accordance with standard procedures [50] by dissolving appropriate amounts of lipids at $\phi=$ neutral lipid $/$ total lipid $(\mathrm{mol} / \mathrm{mol})=0.5$. The encapsulation of Temozolomide (TMZ) into cationic liposomes (CLs) was performed through the dehydration-rehydration method by adding $3 \mathrm{mg}$ TMZ to lipids in molar ratio 1:1 and dissolving the whole mixture in $1 \mathrm{~mL}$ of chloroform and $0.2 \mathrm{~mL}$ of methanol [51]. The mixture was placed on a rotary evaporator for $4 \mathrm{~h}$ at $65^{\circ}$ to produce the film layer. After rehydration with $2.5 \mathrm{~mL}$ of PBS, the solution was extruded 20 times by means of a $0.1 \mu \mathrm{m}$ polycarbonate filter with the Avanti Mini-Extruder (Avanti Polar Lipids, Alabaster, AL, USA) then, subjected to centrifugal filtration with Amicon Ultra-2 mL centrifugal filters (Merck Millipore, Darmstadt, Germany). Finally, the obtained TMZ-loaded CLs were incubated with human plasma (HP) for $1 \mathrm{~h}$ at $37^{\circ} \mathrm{C}$ to form the TMZ-loaded CL biomolecular corona (BC) complexes. 


\subsection{UV-Vis Spectra Measurements}

The TMZ encapsulation efficiency (EE) and drug loading content (DLC) were measured by separating free TMZ from the TMZ Cls using Vivaspin 500 (5 kDa MWCO, GE Healthcare) and performing absorbance measurement of both free and encapsulated TMZ with Jasco V-630 spectrophotometer. Then, we obtained the concentration of TMZ by using the Lambert-Beer law to the $330 \mathrm{~nm}$ absorption peak and we correlated the measured concentration to the sample volume to obtain the absolute amount of free and encapsulated TMZ. Thus, EE and DLC were calculated through Equations (1) and (2) respectively:

$$
\begin{gathered}
\mathrm{EE}=100 \times(\text { mass of the drug in liposome }) /(\text { initial mass of the drug used }) \\
\text { DLC }=100 \times(\text { mass of encapsulated drug }) /(\text { mass of liposome })
\end{gathered}
$$

\subsection{Size and Zeta Potential Experiments}

Size and zeta potential measurements of TMZ-loaded CLs and TMZ-loaded CLs-BC complexes were performed with a Zetasizer Nano ZS90 (Malvern Panalytical, Malvern, UK) at $25^{\circ} \mathrm{C}$. All samples were firstly diluted 1:100 with distilled and data were expressed as mean \pm standard deviation of three replicates. As excess HP was not removed from the suspension of biocoronated CLs, size and zeta-potential measurements refer to the mixture $\mathrm{BC}$ liposomes and HP.

\subsection{Cell Culture}

U87 human glioblastoma cells were purchased from the American Type Culture Collection (ATTC, Manassas, VA, USA). Cells were maintained in Dulbecco's modified Eagle's medium (Sigma-Aldrich, St. Louis, MO, USA) supplemented with 10\% fetal bovine serum (FBS, EuroClone), 2\% penicillin-streptomycin (Sigma-Aldrich) and 2\% L-glutamine (Sigma-Aldrich). Cells were cultivated in T75 flasks and kept at $37^{\circ} \mathrm{C}$ in $5 \% \mathrm{CO}_{2}$ humidity.

\subsection{Spheroid Preparation and Drugs Administration}

U87 human glioblastoma cells were seeded on 96-well, round bottom, ultra-low attachment plates (Corning, Corning, NY, USA) at a density of $0.5 \times 10^{5}$ cells $/ \mathrm{mL}$. The multiwell was centrifuged at $300 \mathrm{~g}$ for $3 \mathrm{~min}$ to ensure the confluence of cells to the centre of the wells. The so-formed single spheroids were incubated at $37^{\circ} \mathrm{C}$ in $5 \% \mathrm{CO}_{2}$ humidity for 3 days before further treatments. CLs containing TMZ were administered to spheroids at a final concentration of $0.5 \mathrm{mg} / \mathrm{mL}$ in two different conditions: pre-incubated with human plasma (Sigma, $1 \mathrm{~h}$ at $37^{\circ} \mathrm{C}$ ), to form protein corona, or without incubation. TMZ alone was administered to spheroids at 0.5 and $1 \mathrm{mg} / \mathrm{mL}$. Control spheroids were used to compare results for both conditions, by administering human plasma or PBS respectively.

\subsection{Spheroid Size and Cell Viability Measurements}

After administration, spheroids were regularly imaged for 14 days at $4 \times$ magnification with Cytation3 Cell Imaging Multi-Mode Reader (BioTek, Winooski, VT, USA), by fixing focal height at $2455 \mu \mathrm{m}$ and by performing auto-correction of the white balance for each well. Size analysis was carried out with ImageJ software [46]. Briefly, spheroid images were converted to 8-bit. A mask was created and the area of each spheroid was measured. Data were normalized by the initial volume (day 0 ) of each spheroid. After the timecourse experiment, cell viability was assessed by the CellTiter-Glo ${ }^{\circledR}$ Luminescent Cell Viability Assay (Promega, Madison, WI, USA). Results were normalized by respective control spheroids. Pristine liposomes (i.e., in the absence of the biomolecular corona) did not show any toxicity and cell viability was around $100 \%$ for all the four formulations.

\section{Results and Discussion}

TMZ encapsulation efficiency (defined as (mass of the drug in liposome)/(initial mass of the drug used) and the correspondent drug loading content (defined as (mass of 
encapsulated drug)/(mass of liposome)) of CLs were obtained by UV-Vis spectra analyses and the results are reported in Table 1. As shown, three out of four formulations exhibited EE values higher than $60 \%$ with CL2 that reached the highest one equal to $77.7 \pm 5.1 \%$. Then, TMZ-loaded CLs were incubated with human plasma (HP) for $1 \mathrm{~h}$ at $37^{\circ} \mathrm{C}$ to form the TMZ-loaded CL-BC complexes.

A thorough characterization of CLs and CL-BC complexes is summarized in Table 2 and Figure 1. Dynamic Light Scattering and Electrophoretic Light Scattering measurements provided size and zeta potential of the investigated systems. TMZ-CLs were small in size (hydrodynamic diameter between 100 and $200 \mathrm{~nm}$ ) and positively charged (zeta potential between 50 and $90 \mathrm{mV}$ ). Statistical differences between the four formulations in regard to all parameters mentioned in Table 2 were evaluated (Supporting Information).

Table 2. Chemical-physical characterization of TMZ-loaded CLs before and after incubation with human plasma (HP). CL1 (DOTAP/cholesterol), CL2 (DOTAP/DOPE), CL3 (DC Chol/DOPE), CL4 (DC-Chol/cholesterol). Zeta deviation is intended as the width distribution as reported by the Malvern Zetasizer software.

\begin{tabular}{lcccc}
\hline & CL1 & CL2 & CL3 & CL4 \\
\hline Size (nm) & $147 \pm 3$ & $151 \pm 11$ & $209 \pm 4$ & $156 \pm 8$ \\
\hline $\begin{array}{l}\text { Size upon } \\
\text { exposure to HP } \\
(\mathrm{nm})\end{array}$ & $240 \pm 37$ & $319 \pm 11$ & $318 \pm 9$ & $316 \pm 37$ \\
\hline PdI & $0.095 \pm 0.013$ & $0.164 \pm 0.037$ & $0.289 \pm 0.020$ & $0.206 \pm 0.116$ \\
\hline $\begin{array}{l}\text { PdI upon } \\
\text { exposure to HP }\end{array}$ & $0.590 \pm 0.049$ & $0.453 \pm 0.019$ & $0.465 \pm 0.030$ & $0.692 \pm 0.195$ \\
\hline $\begin{array}{l}\text { Zeta potential } \\
\text { (mV) }\end{array}$ & $56.8 \pm 1.0$ & $73.8 \pm 1.4$ & $86.4 \pm 0.9$ & $91.4 \pm 0.8$ \\
\hline $\begin{array}{l}\text { Zeta potential } \\
\text { upon exposure } \\
\text { to HP (mV) }\end{array}$ & $-14.2 \pm 0.8$ & $-18.1 \pm 0.8$ & $-14.5 \pm 1.8$ & $-22.8 \pm 0.8$ \\
\hline $\begin{array}{l}\text { Zeta deviation } \\
\text { (mV) }\end{array}$ & $10.2 \pm 0.5$ & $11.8 \pm 0.3$ & $11.8 \pm 0.5$ & $12.1 \pm 0.7$ \\
\hline $\begin{array}{l}\text { Zeta deviation } \\
\text { upon exposure } \\
\text { to HP (mV) }\end{array}$ & $3.9 \pm 0.2$ & $4.9 \pm 0.5$ & $4.7 \pm 1.0$ & $4.0 \pm 0.2$ \\
\hline $\begin{array}{l}\text { Encapsulation } \\
\text { Efficiency }\end{array}$ & $32.5 \pm 1.2 \%$ & $77.7 \pm 5.1 \%$ & $65.3 \pm 4.3 \%$ & $73.5 \pm 3.4 \%$ \\
\hline $\begin{array}{l}\text { Drug Loading } \\
\text { Content }\end{array}$ & $14.9 \pm 0.9 \%$ & $23.9 \pm 3.1 \%$ & $22.9 \pm 2.7 \%$ & $31.7 \pm 1.5 \%$ \\
\hline
\end{tabular}


a

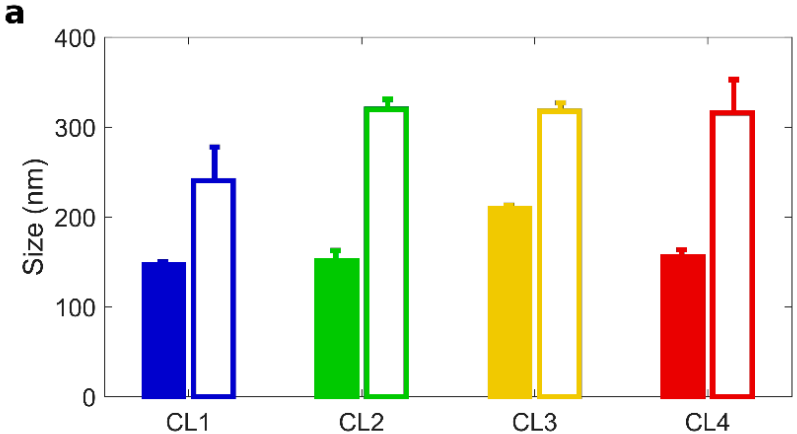

b

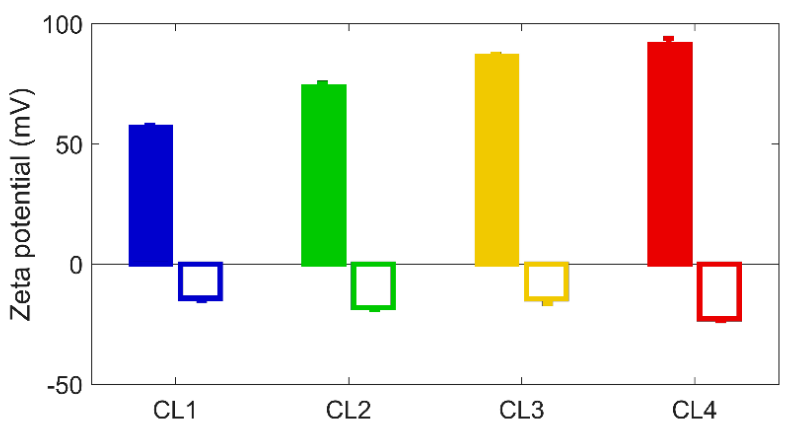

Figure 1. Size and zeta potential of TMZ-loaded CLs with and without BC. Size (a) and zetapotential (b) of Temozolomide (TMZ)-loaded CLs (full histograms) and TMZ-loaded CL biomolecular corona complexes (empty histograms): CL1 (DOTAP/cholesterol), CL2 (DOTAP/DOPE), CL3 (DC Chol/DOPE), CL4 (DC-Chol/cholesterol).

After $1 \mathrm{~h}$ incubation with HP, TMZ-CLs with BC were bigger in size than their counterparts (Figure 1a). The correspondent Polydispersity Indexes (PdI in Table 2) indicate that bare TMZ-CLs were homogenous in size, but TMZ-CLs with BC exhibited wider size distributions. These findings are most likely due to the formation of a thick protein layer at the particle surface leading to aggregation [41]. The inversion of the zeta potential is also caused by protein binding, as most plasma proteins exhibit negative charges at physiological $\mathrm{pH}$. After preparation and chemical-physical characterization, TMZ-CLs with and without $B C$ were diluted to have a final TMZ concentration of $0.5 \mathrm{mg} / \mathrm{mL}$ and administered to 3D spheroids [52]. Anticancer activity against GBM spheroids was evaluated by spheroids size distribution. Area of spheroids was monitored using digital microscopy to assess changes in spheroid size due to cell death and destruction of the spheroid architecture. Figure 2a reported the time course (from 0 to 14 days) of changes in tumor size, expressed as normalized average area, induced by the treatment with TMZ-loaded CLs, free TMZ at two different concentrations $(0.5$ and $1.0 \mathrm{mg} / \mathrm{mL})$ and untreated spheroids as controls. 
a

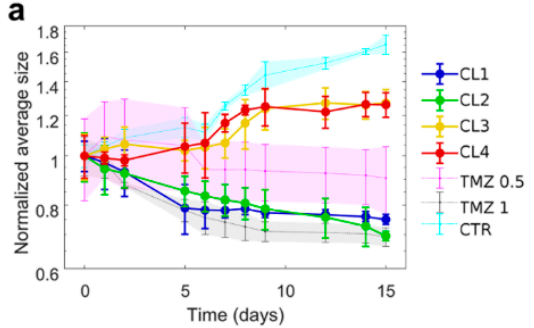

b

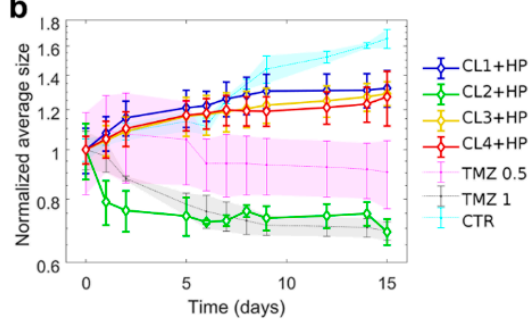

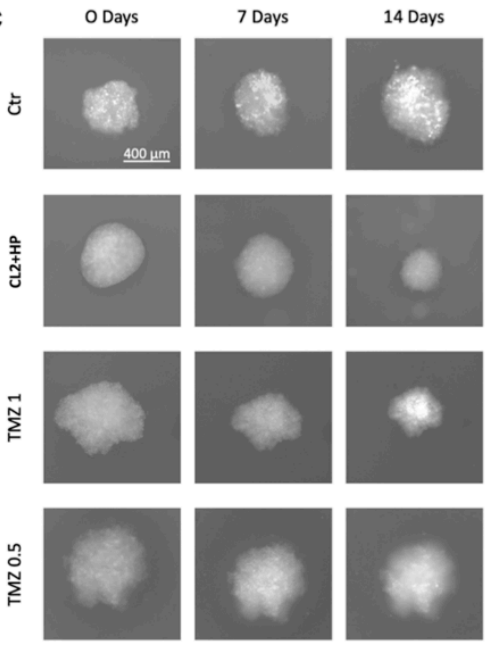

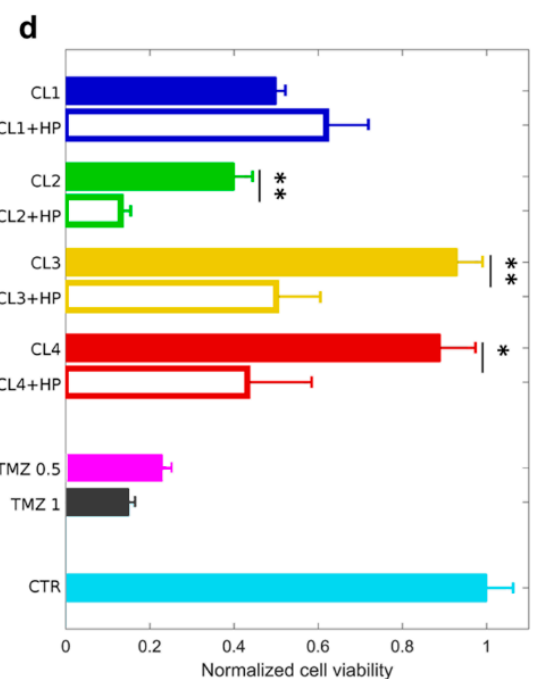

Figure 2. Glioblastoma spheroids treated with TMZ-loaded CLs with and without BC. (a) Spheroid growth in time expressed in terms of normalized average size after the treatment with TMZ-loaded CLs and (b) TMZ-loaded CLs incubated with human plasma (HP). (c) Representative images at 0, 7 and 14 days of glioblastoma spheroids after the treatment with control solution, TMZ-loaded CL2 incubated with human plasma (HP) and free TMZ at two different concentration (0.5 $\mathrm{mg} / \mathrm{mL}$ and $1 \mathrm{mg} / \mathrm{mL}$ ). (d) Cell viability of spheroids after two weeks of treatment with CLs (filled histograms) and CLs incubated with HP (empty histograms). CL1 (DOTAP/cholesterol), CL2 (DOTAP/DOPE), CL3 (DC Chol/DOPE), CL4 (DC-Chol/cholesterol). Statistical significance was evaluated by student's test with respect to CLs incubated with HP. ${ }^{* *} p<0.05, * p<0.001$, no asterisk means not significant.

As depicted, after two weeks normalized average areas of spheroids, treated with TMZloaded CL1 and CL2, strongly reduces, respectively up to $75 \%$ and $69 \%$ with respect to their initial size. By contrast, the treatment with TMZ-loaded CL3 and CL4 seems not to affect cell proliferation. The different trends of the four CLs complexes could be mostly attributed to two possible factors, i.e., non-specific contributions related to the different physicalchemical properties of each complex or specific mechanisms associated to the different complex's chemical compositions, on which mainly depends the molecular recognition at cell membrane level $[53,54]$. The first factor can be excluded since all complexes exhibited roughly the same diameter and surface charge (Table 2). Consequently, lipid composition is expected to play a role in activating specific endocytic pathways [54]. Indeed, CL1 and CL2 are both composed of 50\% of the cationic lipid DOTAP while CL3 and CL4 of $50 \%$ of the cationic DC-Chol. The different composition seems to be the main factor in regulating cell recognition with the result that the presence of DOTAP in TMZ-CL1 and TMZ-CL2 led to a higher internalization and a resultant inhibition of cell growth. Next, since the purpose of the present study was to evaluate the impact of BC on tumor growth, we administrated CLs with BC to the GBM spheroids and measured the corresponding size changes in time (Figure 2b). It is evident that spheroids treated with TMZ-loaded CL2 with $\mathrm{BC}$ abruptly reduced in size already after two days. Thus, the presence of BC would seem to promote the complex' cellular uptake. After two weeks the CL2 complexes with BC reduced spheroid growth with an effect like twice free TMZ $(1 \mathrm{mg} / \mathrm{mL})$. On the contrary, the effect of $\mathrm{BC}$ on the other formulations resulted irrelevant, despite the $\mathrm{BC}$ contributions in terms of size and surface charge was similar to all the complexes. According to recent literature [55], this inequality could be ascribed to a different BC composition that can either promote or inhibit cellular recognition. It was previously demonstrated that CL2 complexes are enriched of typical protein corona fingerprints (PCFs) (i.e., Vitronectin, APOA1, APOA2, APOB, APOC2, Ig heavy chain V-III region BRO, vitamin K-dependent protein and Integrin beta3) that trigger selective association with cancer cells leading to [56,57]. Among identified PCFs, Vitronectin binds to $\alpha \mathrm{v} \beta 3$ integrins, also known as the vitronectin receptor and was exploited to target cancer cells over-expressing $\alpha \mathrm{v} \beta 3$ 
integrins [37]. This is a point of great general interest, as $\alpha \mathrm{V} \beta 3$ integrins are overexpressed on U-87 cell line [58]. Apolipoproteins bind specific lipoprotein receptors, including low-density lipoprotein receptor (LDLR) and scavenger receptor class B type I (SR-BI). LDLR mediates the endocytosis of cholesterol-rich LDL, whereas SR-BI is a high-density lipoprotein (HDL) receptor that promotes cell internalization of cholesterol esters from circulating lipoproteins. Notably, both LDLR and SR-BI are upregulated in human gliomas and play an important role in the delivery and accumulation of cargos into human U-87 cells $[59,60]$. Importantly, it was not possible to measure spheroids treated with human plasma alone, since it caused spheroid disaggregation and invasion, as it has already been reported in literature [61]. For a complete view, in Figure 2c we reported the microscopy images of GBM spheroid size evolution from 0 to 7 and 14 days after administration with TMZ loaded CL2 with BC complexes in comparison with free TMZ and untreated spheroids. As a confirmation of previous findings, the images manifested the similarity between the size of spheroids treated with BC-CL2 complexes and free TMZ $(1 \mathrm{mg} / \mathrm{mL})$. According to these results, it is clear how the presence of $\mathrm{BC}$ does not have a unique effect on tumor growth. Thus, to have an exhaustive understanding of its influence on tumor activity, after two weeks we performed cell viability measurements on spheroids treated with TMZ-CLs with and without BC (Figure 2d). Except for TMZ-CL1 where the presence of $B C$ seems not to significantly affect the viability compared to the counterpart without $\mathrm{BC}$ (respectively $0.62 \pm 0.09$ and $0.5 \pm 0.01$ ), for the other three complexes the reduction of cell viability is strongly stressed by the presence of BC. In particular, CL2 both with and without previous incubation with $\mathrm{HP}$, exerted a significant reduction up to $0.13 \pm 0.01$ and $0.40 \pm 0.03$, respectively, similarly to free $\mathrm{TMZ}$ at $1 \mathrm{mg} / \mathrm{mL}(0.15 \pm 0.003)$. By comparing tumor growth analysis and viability assay it is possible to draw some conclusions. Notably, except for CL2 complexes where BC displayed a remarkable impact both in size tumor decrease and cell viability, for the other cases there is a discrepancy between tumor growth trends and viability results. Specifically, BC, in most cases, did not exhibit an inhibitory effect on spherical growth but, on the other hand, had a significant impact on decreasing cell viability. A striking example is represented by TMZ-CL4 where the presence of BC had an irrelevant effect on spheroid size but not on cell viability that is reduced up to $0.43 \pm 0.14$. This divergence could depend on different aspects specifically related to the $3 \mathrm{D}$ cultures behavior. In the literature, several works correlate viability assays to the size growth trends of 3D cultures [49,62]. When dealing with a 3D culture growth analysis, it must be considered factors as cell density of the spheroid and cell cohesion. These two factors together are usually used to get a better estimate of the effective spheroid volume [63]. A decrease in cell adhesion corresponds to a decrease in density and an increase in spheroid volume. How does this relate to cytotoxicity? When cells begin to die, the ones that compose the peripheral region of the spheroid adhere less to each other, this phenomenon leads to an initial increase in the spheroid volume. After that, there is a consequential dissociation of the peripheral cells that cause a volume decrease. Thus, it is not always true that a decrease in cell viability is related to a decrease in spheroid area. To have a more reliable correlation between viability and spheroid growth, cell cohesion assays and density measurements should be developed in parallel. In conclusion, the effect of BC on the anticancer activity of TMZ-loaded CLs in a GBM spheroid culture was evaluated by means of spheroid size trends and cell viability assay. The results indicated a non-unique effect of the corona for all the complexes, especially regarding the tumor growth trends. An outstanding result was reported by TMZ-CL2 formulation with BC, that caused a notable reduction of tumor size in line with a considerable decrease of cell viability. This finding demonstrated that the exploitation of $\mathrm{BC}$ could be a helpful strategy to perform targeting nanodevice able to overcome the BBB and improve anticancer efficacy. However, further investigations are needed to better understand the mechanism behind cellular uptake in GBM spheroids' cultures. 


\section{Conclusions}

BC on the anticancer activity of TMZ-loaded CLs in a GBM spheroid culture was evaluated by means of spheroid size trends and cell viability assay. The results indicated a non-unique effect of the corona for all the complexes, especially regarding the tumor growth trends. An outstanding result was reported by TMZ-CL2 formulation with BC, that caused a notable reduction of tumor size in line with a considerable decrease of cell viability. This finding demonstrated that the exploitation of $\mathrm{BC}$ could be a helpful strategy to perform targeting nanodevice able to target brain cancer cells and improve anticancer efficacy.

Author Contributions: Conceptualization: G.C.; Data curation: L.D.; Formal Analysis: G.P., L.D.; Funding acquisition: M.P., D.P., G.C.; Investigation: G.P., F.G., L.D., E.Q., A.A.; Project administration: M.P., G.C.; Resources: M.P., D.P., G.C.; Software: A.A.; Supervision: V.P., M.P., D.P., G.C.; Validation: G.P., F.G., V.P.; Visualization: G.P., V.P.; Writing—original draft: E.Q.; Writing—review and editing: M.P., D.P., G.C. All authors have read and agreed to the published version of the manuscript.

Funding: This research received no external funding. The APC was funded by Sapienza University of Rome.

Institutional Review Board Statement: Not applicable.

Informed Consent Statement: Not applicable.

Data Availability Statement: The datasets generated during and/or analyzed during the current study are available from the corresponding authors (M.P. and G.C.) on reasonable request.

Conflicts of Interest: The authors declare no conflict of interest.

\section{References}

1. Fan, Y.; Avci, N.G.; Nguyen, D.T.; Dragomir, A.; Akay, Y.M.; Xu, F.; Akay, M. Engineering a high-throughput 3-D in vitro glioblastoma model. IEEE J. Transl. Eng. Health Med. 2015, 3, 4300108. [CrossRef] [PubMed]

2. Groneberg, D.A.; Addicks, A.-M.; Bendels, M.H.; Quarcoo, D.; Jaque, J.; Brüggmann, D. Glioblastoma research: US and international networking achievements. Oncotarget 2017, 8, 115730. [CrossRef] [PubMed]

3. Ramirez, Y.P.; Weatherbee, J.L.; Wheelhouse, R.T.; Ross, A.H. Glioblastoma multiforme therapy and mechanisms of resistance. Pharmaceuticals 2013, 6, 1475-1506. [CrossRef] [PubMed]

4. Seymour, T.; Nowak, A.; Kakulas, F. Targeting aggressive cancer stem cells in glioblastoma. Front. Oncol. 2015, 5, 159. [CrossRef] [PubMed]

5. Nagasawa, D.T.; Chow, F.; Yew, A.; Kim, W.; Cremer, N.; Yang, I. Temozolomide and other potential agents for the treatment of glioblastoma multiforme. Neurosurg. Clin. N. Am. 2012, 23, 307-322. [CrossRef] [PubMed]

6. Kim, S.-S.; Harford, J.B.; Pirollo, K.F.; Chang, E.H. Effective treatment of glioblastoma requires crossing the blood-brain barrier and targeting tumors including cancer stem cells: The promise of nanomedicine. Biochem. Biophys. Res. Commun. 2015, 468, 485-489. [CrossRef]

7. Abbott, N.J. Blood-brain barrier structure and function and the challenges for CNS drug delivery. J. Inherit. Metab. Dis. 2013, 36, 437-449. [CrossRef]

8. Perini, G.; Palmieri, V.; Ciasca, G.; De Spirito, M.; Papi, M. Unravelling the Potential of Graphene Quantum Dots in Biomedicine and Neuroscience. Int. J. Mol. Sci. 2020, 21, 3712. [CrossRef]

9. Kim, S.-S.; Rait, A.; Kim, E.; DeMarco, J.; Pirollo, K.F.; Chang, E.H. Encapsulation of temozolomide in a tumor-targeting nanocomplex enhances anti-cancer efficacy and reduces toxicity in a mouse model of glioblastoma. Cancer Lett. 2015, 369, 250-258. [CrossRef] [PubMed]

10. Xi, G.; Robinson, E.; Mania-Farnell, B.; Vanin, E.F.; Shim, K.-W.; Takao, T.; Allender, E.V.; Mayanil, C.S.; Soares, M.B.; Ho, D. Convection-enhanced delivery of nanodiamond drug delivery platforms for intracranial tumor treatment. Nanomed. Nanotechnol. Biol. Med. 2014, 10, 381-391. [CrossRef] [PubMed]

11. Perini, G.; Palmieri, V.; Ciasca, G.; D’Ascenzo, M.; Gervasoni, J.; Primiano, A.; Rinaldi, M.; Fioretti, D.; Prampolini, C.; Tiberio, F. Graphene Quantum Dots' Surface Chemistry Modulates the Sensitivity of Glioblastoma Cells to Chemotherapeutics. Int. J. Mol. Sci. 2020, 21, 6301. [CrossRef]

12. Perini, G.; Palmieri, V.; Ciasca, G.; Primiano, A.; Gervasoni, J.; De Spirito, M.; Papi, M. Functionalized Graphene Quantum Dots Modulate Malignancy of Glioblastoma Multiforme by Downregulating Neurospheres Formation. C 2021, 7, 4.

13. Perini, G.; Palmieri, V.; Ciasca, G.; D’Ascenzo, M.; Primiano, A.; Gervasoni, J.; De Maio, F.; De Spirito, M.; Papi, M. Enhanced Chemotherapy for Glioblastoma Multiforme Mediated by Functionalized Graphene Quantum Dots. Materials 2020, 13, 4139. [CrossRef] 
14. Friedman, H.S.; Kerby, T.; Calvert, H. Temozolomide and treatment of malignant glioma. Clin. Cancer Res. 2000, 6, $2585-2597$. [PubMed]

15. Ramalho, M.J.; Coelho, M.A.; Pereira, M.C. Nanocarriers for the delivery of temozolomide in the treatment of glioblastoma: A review. Des. Dev. New Nanocarr. 2018, 687-722. [CrossRef]

16. Krol, S.; Macrez, R.; Docagne, F.; Defer, G.; Laurent, S.; Rahman, M.; Hajipour, M.J.; Kehoe, P.G.; Mahmoudi, M. Therapeutic benefits from nanoparticles: The potential significance of nanoscience in diseases with compromise to the blood brain barrier. Chem. Rev. 2013, 113, 1877-1903. [CrossRef] [PubMed]

17. Xu, Y.; Shen, M.; Li, Y.; Sun, Y.; Teng, Y.; Wang, Y.; Duan, Y. The synergic antitumor effects of paclitaxel and temozolomide co-loaded in mPEG-PLGA nanoparticles on glioblastoma cells. Oncotarget 2016, 7, 20890. [CrossRef] [PubMed]

18. Fan, L.; Yang, Q.; Tan, J.; Qiao, Y.; Wang, Q.; He, J.; Wu, H.; Zhang, Y. Dual loading miR-218 mimics and temozolomide using AuCOOH@ FA-CS drug delivery system: Promising targeted anti-tumor drug delivery system with sequential release functions. J. Exp. Clin. Cancer Res. 2015, 34, 106. [CrossRef]

19. Ling, Y.; Wei, K.; Zou, F.; Zhong, S. Temozolomide loaded PLGA-based superparamagnetic nanoparticles for magnetic resonance imaging and treatment of malignant glioma. Int. J. Pharm. 2012, 430, 266-275. [CrossRef]

20. Dilnawaz, F.; Sahoo, S.K. Enhanced accumulation of curcumin and temozolomide loaded magnetic nanoparticles executes profound cytotoxic effect in glioblastoma spheroid model. Eur. J. Pharm. Biopharm. 2013, 85, 452-462. [CrossRef]

21. Jain, A.; Chasoo, G.; Singh, S.K.; Saxena, A.K.; Jain, S.K. Transferrin-appended PEGylated nanoparticles for temozolomide delivery to brain: In vitro characterisation. J. Microencapsul. 2011, 28, 21-28. [CrossRef] [PubMed]

22. Patel, B.K.; Parikh, R.H. Formulation development and evaluation of temozolomide loaded hydrogenated soya phosphatidylcholine liposomes for the treatment of brain cancer. Asian J. Pharm. Clin. Res. 2016, 9, 340-343.

23. Palchetti, S.; Pozzi, D.; Marchini, C.; Amici, A.; Andreani, C.; Bartolacci, C.; Digiacomo, L.; Gambini, V.; Cardarelli, F.; Di Rienzo, C. Manipulation of lipoplex concentration at the cell surface boosts transfection efficiency in hard-to-transfect cells. Nanomed. Nanotechnol. Biol. Med. 2017, 13, 681-691. [CrossRef]

24. Liu, Q.; Zhou, L.; Lu, R.; Yang, C.; Wang, S.; Hai, L.; Wu, Y. Biotin and glucose co-modified multi-targeting liposomes for efficient delivery of chemotherapeutics for the treatment of glioma. Bioorg. Med. Chem. 2021, 29, 115852. [CrossRef] [PubMed]

25. Monopoli, M.P.; Åberg, C.; Salvati, A.; Dawson, K.A. Biomolecular coronas provide the biological identity of nanosized materials. Nat. Nanotechnol. 2012, 7, 779. [CrossRef] [PubMed]

26. Wilhelm, S.; Tavares, A.J.; Dai, Q.; Ohta, S.; Audet, J.; Dvorak, H.F.; Chan, W.C. Analysis of nanoparticle delivery to tumours. Nat. Rev. Mater. 2016, 1, 16014. [CrossRef]

27. Caracciolo, G. Clinically approved liposomal nanomedicines: Lessons learned from the biomolecular corona. Nanoscale 2018, 10, 4167-4172. [CrossRef] [PubMed]

28. Digiacomo, L.; Pozzi, D.; Palchetti, S.; Zingoni, A.; Caracciolo, G. Impact of the protein corona on nanomaterial immune response and targeting ability. WIREs Nanomed. Nanobiotechnol. 2020, 12, e1615. [CrossRef] [PubMed]

29. Walczyk, D.; Bombelli, F.B.; Monopoli, M.P.; Lynch, I.; Dawson, K.A. What the cell "sees" in bionanoscience. J. Am. Chem. Soc. 2010, 132, 5761-5768. [CrossRef]

30. Mahmoudi, M. Protein corona: The golden gate to clinical applications of nanoparticles. Int. J. Biochem. Cell Biol. 2016, 100, 141-142. [CrossRef] [PubMed]

31. Giulimondi, F.; Digiacomo, L.; Pozzi, D.; Palchetti, S.; Vulpis, E.; Capriotti, A.L.; Chiozzi, R.Z.; Laganà, A.; Amenitsch, H.; Masuelli, L. Interplay of protein corona and immune cells controls blood residency of liposomes. Nat. Commun. 2019, 10, 3686. [CrossRef]

32. Palchetti, S.; Pozzi, D.; Capriotti, A.L.; La Barbera, G.; Chiozzi, R.Z.; Digiacomo, L.; Peruzzi, G.; Caracciolo, G.; Laganà, A. Influence of dynamic flow environment on nanoparticle-protein corona: From protein patterns to uptake in cancer cells. Colloids Surf. B Biointerfaces 2017, 153, 263-271. [CrossRef] [PubMed]

33. Gräfe, C.; Weidner, A.; vd Lühe, M.; Bergemann, C.; Schacher, F.H.; Clement, J.H.; Dutz, S. Intentional formation of a protein corona on nanoparticles: Serum concentration affects protein corona mass, surface charge, and nanoparticle-cell interaction. Int. J. Biochem. Cell Biol. 2016, 75, 196-202. [CrossRef]

34. Ge, C.; Tian, J.; Zhao, Y.; Chen, C.; Zhou, R.; Chai, Z. Towards understanding of nanoparticle-protein corona. Arch. Toxicol. 2015, 89, 519-539. [CrossRef]

35. Ritz, S.; Schoöttler, S.; Kotman, N.; Baier, G.; Musyanovych, A.; Kuharev, J.r.; Landfester, K.; Schild, H.r.; Jahn, O.; Tenzer, S. Protein corona of nanoparticles: Distinct proteins regulate the cellular uptake. Biomacromolecules 2015, 16, 1311-1321. [CrossRef] [PubMed]

36. Lara, S.; Alnasser, F.; Polo, E.; Garry, D.; Lo Giudice, M.C.; Hristov, D.R.; Rocks, L.; Salvati, A.; Yan, Y.; Dawson, K.A. Identification of receptor binding to the biomolecular corona of nanoparticles. ACS Nano 2017, 11, 1884-1893. [CrossRef]

37. Caracciolo, G.; Cardarelli, F.; Pozzi, D.; Salomone, F.; Maccari, G.; Bardi, G.; Capriotti, A.L.; Cavaliere, C.; Papi, M.; Laganà, A. Selective targeting capability acquired with a protein corona adsorbed on the surface of 1,2-dioleoyl-3-trimethylammonium propane/dna nanoparticles. ACS Appl. Mater. Interfaces 2013, 5, 13171-13179. [CrossRef] 
38. Gaillard, P.J.; Appeldoorn, C.C.; Dorland, R.; van Kregten, J.; Manca, F.; Vugts, D.J.; Windhorst, B.; van Dongen, G.A.; de Vries, H.E.; Maussang, D. Pharmacokinetics, brain delivery, and efficacy in brain tumor-bearing mice of glutathione pegylated liposomal doxorubicin (2B3-101). PLoS ONE 2014, 9, e82331. [CrossRef] [PubMed]

39. Cox, A.; Andreozzi, P.; Dal Magro, R.; Fiordaliso, F.; Corbelli, A.; Talamini, L.; Chinello, C.; Raimondo, F.; Magni, F.; Tringali, M. Evolution of nanoparticle protein corona across the blood-brain barrier. ACS Nano 2018, 12, 7292-7300. [CrossRef]

40. Zhang, Z.; Guan, J.; Jiang, Z.; Yang, Y.; Liu, J.; Hua, W.; Mao, Y.; Li, C.; Lu, W.; Qian, J. Brain-targeted drug delivery by manipulating protein corona functions. Nat. Commun. 2019, 10, 3561. [CrossRef]

41. Arcella, A.; Palchetti, S.; Digiacomo, L.; Pozzi, D.; Capriotti, A.L.; Frati, L.; Oliva, M.A.; Tsaouli, G.; Rota, R.; Screpanti, I. Brain targeting by liposome-biomolecular corona boosts anticancer efficacy of temozolomide in glioblastoma cells. ACS Chem. Neurosci. 2018, 9, 3166-3174. [CrossRef]

42. Caracciolo, G.; Caminiti, R.; Digman, M.A.; Gratton, E.; Sanchez, S. Efficient escape from endosomes determines the superior efficiency of multicomponent lipoplexes. J. Phys. Chem. B 2009, 113, 4995-4997. [CrossRef] [PubMed]

43. Pozzi, D.; Caracciolo, G.; Caminiti, R.; De Sanctis, S.C.; Amenitsch, H.; Marchini, C.; Montani, M.; Amici, A. Toward the Rational Design of Lipid Gene Vectors: Shape Coupling between Lipoplex and Anionic Cellular Lipids Controls the Phase Evolution of Lipoplexes and the Efficiency of DNA Release. ACS Appl. Mater. Interfaces 2009, 1, 2237-2249. [CrossRef] [PubMed]

44. Pozzi, D.; Marchini, C.; Cardarelli, F.; Rossetta, A.; Colapicchioni, V.; Amici, A.; Montani, M.; Motta, S.; Brocca, P.; Cantù, L.; et al. Mechanistic understanding of gene delivery mediated by highly efficient multicomponent envelope-type nanoparticle systems. Mol. Pharm. 2013, 10, 4654-4665. [CrossRef]

45. Caracciolo, G.; Pozzi, D.; Caminiti, R.; Marchini, C.; Montani, M.; Amici, A.; Amenitsch, H. Enhanced transfection efficiency of multicomponent lipoplexes in the regime of optimal membrane charge density. J. Phys. Chem. B 2008, 112, 11298-11304. [CrossRef] [PubMed]

46. Moriconi, C.; Palmieri, V.; Di Santo, R.; Tornillo, G.; Papi, M.; Pilkington, G.; De Spirito, M.; Gumbleton, M. INSIDIA: A FIJI Macro Delivering High-Throughput and High-Content Spheroid Invasion Analysis. Biotechnol. J. 2017, 12, 1700140. [CrossRef]

47. Akay, M.; Hite, J.; Avci, N.G.; Fan, Y.; Akay, Y.; Lu, G.; Zhu, J.-J. Drug screening of human GBM spheroids in brain cancer chip. Sci. Rep. 2018, 8, 15423. [CrossRef] [PubMed]

48. Kitahara, M.; Katakura, R.; Suzuki, J.; Sasaki, T. Experimental combination chemotherapy of ACNU and 5-FU against cultured glioma model (spheroid) and subcutaneous rat glioma. Int. J. Cancer 1987, 40, 557-563. [CrossRef]

49. Longati, P.; Jia, X.; Eimer, J.; Wagman, A.; Witt, M.-R.; Rehnmark, S.; Verbeke, C.; Toftgård, R.; Löhr, M.; Heuchel, R.L. 3D pancreatic carcinoma spheroids induce a matrix-rich, chemoresistant phenotype offering a better model for drug testing. BMC Cancer 2013, 13, 95. [CrossRef]

50. Caracciolo, G.; Marchini, C.; Pozzi, D.; Caminiti, R.; Amenitsch, H.; Montani, M.; Amici, A. Structural stability against disintegration by anionic lipids rationalizes the efficiency of cationic liposome/DNA complexes. Langmuir 2007, 23, 4498-4508. [CrossRef]

51. McFaline-Figueroa, J.R.; Lee, E.Q. Brain tumors. Am. J. Med. 2018, 131, 874-882. [CrossRef]

52. Liu, Y.-J.; Ma, Y.-C.; Zhang, W.-J.; Yang, Z.-Z.; Liang, D.-S.; Wu, Z.-F.; Qi, X.-R. Combination therapy with micellarized cyclopamine and temozolomide attenuate glioblastoma growth through Gli1 down-regulation. Oncotarget 2017, 8, 42495. [CrossRef]

53. Marchini, C.; Pozzi, D.; Montani, M.; Alfonsi, C.; Amici, A.; Amenitsch, H.; Candeloro De Sanctis, S.; Caracciolo, G. Tailoring lipoplex composition to the lipid composition of plasma membrane: A Trojan horse for cell entry? Langmuir 2010, 26, 13867-13873. [CrossRef]

54. Abumanhal-Masarweh, H.; da Silva, D.; Poley, M.; Zinger, A.; Goldman, E.; Krinsky, N.; Kleiner, R.; Shenbach, G.; Schroeder, J.E.; Shklover, J. Tailoring the lipid composition of nanoparticles modulates their cellular uptake and affects the viability of triple negative breast cancer cells. J. Control. Release 2019, 307, 331-341. [CrossRef] [PubMed]

55. Yang, K.; Mesquita, B.; Horvatovich, P.; Salvati, A. Tuning liposome composition to modulate corona formation in human serum and cellular uptake. Acta Biomater. 2020, 106, 314-327. [CrossRef]

56. Bigdeli, A.; Palchetti, S.; Pozzi, D.; Hormozi-Nezhad, M.R.; Baldelli Bombelli, F.; Caracciolo, G.; Mahmoudi, M. Exploring Cellular Interactions of Liposomes Using Protein Corona Fingerprints and Physicochemical Properties. ACS Nano 2016, 10, $3723-3737$. [CrossRef] [PubMed]

57. Palchetti, S.; Digiacomo, L.; Pozzi, D.; Peruzzi, G.; Micarelli, E.; Mahmoudi, M.; Caracciolo, G. Nanoparticles-cell association predicted by protein corona fingerprints. Nanoscale 2016, 8, 12755-12763. [CrossRef]

58. Benedetto, S.; Pulito, R.; Crich, S.G.; Tarone, G.; Aime, S.; Silengo, L.; Hamm, J. Quantification of the expression level of integrin receptor $\alpha \mathrm{v} \beta 3$ in cell lines and MR imaging with antibody-coated iron oxide particles. Magn. Reson. Med. 2006, 56, 711-716. [CrossRef]

59. Kascakova, S.; Nadova, Z.; Mateasik, A.; Mikes, J.; Huntosova, V.; Refregiers, M.; Sureau, F.; Maurizot, J.C.; Miskovsky, P.; Jancura, D. High level of low-density lipoprotein receptors enhance hypericin uptake by U-87 MG cells in the presence of LDL. Photochem. Photobiol. 2008, 84, 120-127. [CrossRef] [PubMed]

60. Berney, E.; Sabnis, N.; Panchoo, M.; Raut, S.; Dickerman, R.; Lacko, A.G. The SR-B1 receptor as a potential target for treating glioblastoma. J. Oncol. 2019, 2019. [CrossRef]

61. Burleson, K.M.; Boente, M.P.; Pambuccian, S.E.; Skubitz, A.P. Disaggregation and invasion of ovarian carcinoma ascites spheroids. J. Transl. Med. 2006, 4, 6. [CrossRef] [PubMed] 
62. Scolamiero, G.; Pazzini, C.; Bonafè, F.; Guarnieri, C.; Muscari, C. Effects of $\alpha$-mangostin on viability, growth and cohesion of multicellular spheroids derived from human breast cancer cell lines. Int. J. Med. Sci. 2018, 15, 23. [CrossRef] [PubMed]

63. Mikhail, A.S.; Eetezadi, S.; Allen, C. Multicellular tumor spheroids for evaluation of cytotoxicity and tumor growth inhibitory effects of nanomedicines in vitro: A comparison of docetaxel-loaded block copolymer micelles and Taxotere ${ }^{\circledR}$. PLoS ONE 2013, 8, e62630. [CrossRef] [PubMed] 